\title{
Prevalence, Clinical Presentation and Patterns of Thyroid Disorders Among Anterior Neck Mass Patients Visiting Jimma Medical Center, Southwest Ethiopia
}

\author{
Shifa Toyib ${ }^{1}$, Teshome Kabeta ${ }^{2}$, Getahun Dendir ${ }^{3}$, Moyeta Bariso ${ }^{4}$ and Wondu Reta*4 \\ ${ }^{1}$ Jimma University, Institute of Health, School of Medicine, Department of Internal Medicine, Jimma, Ethiopia \\ ${ }_{2}^{2}$ Jimma University, Institute of Health, College of public health, Department of Epidemiology and Biostatistics, Jimma, Ethiopia \\ ${ }^{3}$ Wolaita Sodo University, School of Medicine, Department of Anesthesia, Wolaita Sodo, Ethiopia \\ ${ }^{4}$ Jimma University, Institute of Health, School of Medicine, Department of Biomedical Sciences, Jimma, Ethiopia \\ *Corresponding author: Wondu Reta Demissie, Jimma University, Institute of Health, School of Medicine, Department of \\ Biomedical sciences, Jimma, Ethiopia
}

\begin{tabular}{l}
\hline ARTICLE INFO \\
\hline Received: May 14, 2019 \\
Published: May 23, 2019 \\
\hline Citation: Shifa Toyib, Teshome Kabeta, \\
Getahun Dendir, Moyeta Bariso, Won- \\
du Reta. Prevalence, Clinical Presenta- \\
tion and Patterns of Thyroid Disorders \\
Among Anterior Neck Mass Patients Vis- \\
iting Jimma Medical Center, Southwest \\
Ethiopia. Biomed J Sci \& Tech Res 18(2)- \\
2019. BJSTR. MS.ID.003126.
\end{tabular}

Keywords: Thyroid Disorders; Magnitude; Clinical Presentation; Thyroid Function Test

\section{ABSTRACT}

Background: Thyroid disorders refer to benign or malignant condition affecting the structure and function of the thyroid gland that may present as a derangement of thyroid hormone secretion, thyroid enlargement or pain. Thyroid disease is a global health problem and the most common type of endocrine disorders next to diabetic mellitus accounting around $30 \%$ to $40 \%$ burden of the endocrine disorder.

Objective: The present study was aimed to assess the magnitude and pattern of thyroid disorders among patients with anterior neck mass visiting Jimma Medical Center (JMC) based upon clinical decision and serum levels of thyroid function test (TFT) in 2018 G.C.

Methods: A cross- sectional study was employed among the sampled 239 patients, with anterior neck mass visiting JMC. Data was collected after written and informed consent was obtained by using structured questionnaire, physical examination and laboratory measurements. TFT was done by measuring serum TSH, FT4, and FT3 levels by electro-chemiluminescence immune assay method at JMC laboratory. Data was entered into Epidata version 3.1 and exported to SPSS version 22 for analysis. The data was processed, summarized and presented in the form of narratives, tables, graphs or figures.

Result: A total of 239 patients with anterior neck mass visiting outpatient clinic of JMC were recruited in the study with mean age of $41.83 \pm 17.52$ SD years ranged from 18 to 90 years. Majority of the patients were females 212 (88.7\%) while the left $27(11.3 \%)$ were males; $155(64.8 \%)$ of the study subjects were living in rural part while the rest $84(35.2 \%)$ were from urban. Majority of the patients were belonged to stage II [117 $(48.9 \%)]$ while others were allocated to stage III [86 (36\%)], stage IB [30 (12.6\%)] and stage IA [6 (2.5\%)]. The mean of TSH was $0.95 \pm 49$ and $0.83 \pm 56$ among males and females respectively while the mean of FT3 ( $4.58 \pm 38$ vs. $4.27 \pm 86$ vs.) and FT4 $(15.47 \pm 92$ vs. 14.98 \pm 44 ) among males and females respectively. The magnitude of signs and symptoms of patients with highest frequency were heat intolerance, irregular pulse, palpitation, cold intolerance, tachycardia, hypertension, weight gain, swelling, poor memory, weight loss and menstrual irregulaty. The discriminated types of thyroid disorders were euthyroidism 83 (34.7\%), sub-clinical hypothyroidism 46 (19.2\%), sub-clinical hyperthyroidism 42 (17.6\%), hypothyroidism 35 (14.6\%) and hyperthyroidism 33 (13.8\%).

Conclusion and Recommendation: Continous assessment of patients with anterior neck mass needs due emphasis for the overall management modality in preventing morbidity and mortality associated due to systemic exacerbation of the disease. 


\section{Introduction}

Thyroid gland secrets thyroid hormones which are essential for growth, neuronal development, reproduction and regulation of energy metabolism [1]. Thyroid diseases/disorders/dysfunction refer to benign or malignant condition affecting the structure and function of the thyroid gland that may present as a derangement of thyroid hormone secretion, thyroid enlargement or pain. Thyroid disease is a global health problem that can substantially impact well-being, as it is one of the most common endocrine disorder next to diabetic mellitus accounting around $30 \%$ to $40 \%$ of the endocrine disorders [2,3]. The prevalence of thyroid disorders was the highest in Africa and WHO revealed that the continent represents over $25 \%$ of the global burden of the disease [4]. Thyroid dysfunction is common, readily identifiable and easily treatable, but if undiagnosed or untreated, it can have profound adverse effects. Thus, timely screening, discriminating types and management is mandatory because the ultimate goal of establishing routine screening programs is to provide appropriate timely treatment, prevent complications and reduce morbidity and mortality related to disease $[5,6]$. Thus, the present study was aimed to assess the magnitude and pattern of thyroid disorders among patients with anterior neck mass visiting JMC based upon clinical decision and serum levels of TFTs.

\section{Methods and Materials}

\section{Study Area and Setting}

The study was conducted in outpatient, medical and surgical clinic of Jimma Medical Center (JMC) among patients with anterior neck mass in 2018 GC. JMC is one of the specialized referral teaching hospitals in the country providing health service at inpatient and outpatient level for the catchment of over 15 million populations in the southwest of the country. JMC has no endocrine clinic and patients with known thyroid disorders have follow up and visiting at the outpatient, medical and surgical clinic of the hospital.

\section{Data Collection Method}

A structured questionnaire was used to obtain sociodemographic characteristics and variables related to symptoms of thyroid dysfunction. Pertinent finding/signs were also recorded after physical investigation. Serum level of thyroid hormones (TSH, T3, T4) were measured by electro-chemiluminescence immune assay method at JMC laboratory.

\section{Data Processing and Analysis}

Data was entered into EpiData version 3.1 and exported to SPSS version 22.0 for analysis after checking for missing and outlier. Descriptive findings were reported by proportions, frequency distribution, tables, graphic presentation and narration.

\section{Ethical Consideration}

Ethical clearance to conduct the study was obtained from the ethical review board of Jimma University, before official commencement of the data collection process. Written and orally informed consent was obtained from all patients before data collection. Patient's confidentiality, equity of services and interests of patients was ensured during the study period.

Definition of terms in the study (operational definition)

\section{Thyroid Function Status}

a. Euthyroid: refers to normal level of TSH $(0.45-4.5$ $\mathrm{mIU} / \mathrm{L})$, FT3 (2.3 -6.3 pmol/l), FT4(10.3-24.5 pmol/l) [7].

b. Subclinical Hypothyroidism: is an elevation in serum TSH (>4.5 mIU/L) with normal serumFT4(10.3- $24.5 \mathrm{pmol} / \mathrm{l})$ and FT3 (2.3-6.3 pmol/l) [6-10].

c. Hypothyrodisim: is an elevation in serum TSH $(>4.5$ mIU/L) with low serum FT4 $(<10.3 \mathrm{pmol} / \mathrm{l})$ and FT3 $(<2.3$ pmol/l) concentration $[7,11]$.

d. Subclinical Hyperthyrodisim: low serum TSH $(<0.45$ mIU/L), but normal level of FT3 and FT4 $[7,12,13]$.

e. Hyperthyroidism: If serum TSH is low $(<0.45 \mathrm{mU} / \mathrm{l})$ and FT4 $>24.5 \mathrm{pmol} / \mathrm{l}$ or FT3 $>6.3 \mathrm{pmol} /$ lor both $[7,11]$.

4.4.2.Grading Goiter According to World Health Organization (WHO) Goiter Grading System [14,15]:

a. Stage IA: Goiter detectable only by palpation and not visible even when the neck is fully extended.

b. Stage I B: Goiter palpable but visible only when the neck is fully extended.

c. Stage II: Goiter visible with the neck in normal position. Palpation is not needed for diagnosis

d. Stage III: Very large goiter that can be recognized at a consideration.

\section{Results}

\section{Socio-Demographic Characteristics of Patients with Anterior Neck Mass}

A total of 239 patients with anterior neck mass visiting outpatient clinic of JMC were recruited in the study, with mean age of $41.83 \pm 17.52$ SD years ranged from 18 to 90 years. Majority of the patients were female $212(88.7 \%)$ while the left $27(11.3 \%)$ were male. About 155 (64.8\%) of the study subjects were living in rural part while the rest 84 (35.2\%) were from urban (Table 1).

Table 1: Socio-demographic characteristics patients with anterior neck mass at JMC, 2018 G.C.

\begin{tabular}{|c|c|}
\hline Parameter & Statistics \\
\hline $\begin{array}{c}\text { Sex, Number }(\%) \\
\text { Female }\end{array}$ & $212(88.7 \%)$ \\
\hline Male & $27(11.3 \%)$ \\
\hline Age, mean \pm SD years & $41.83 \pm 17.52$ \\
\hline
\end{tabular}




\begin{tabular}{|c|c|}
\hline $\begin{array}{c}\text { Residency, Number (\%) } \\
\text { Rural }\end{array}$ & $155(64.8 \%)$ \\
\hline Urban & $84(35.2 \%)$ \\
\hline
\end{tabular}

\section{Grades of Anterior Neck Mass}

As grading of anterior neck mass/goiter was performed according to World Health Organization (WHO) Goiter Grading System, majority of the patients were belonged to stage II 117 (48.9\%) while others were stage III 86 (36\%), stage IB 30 (12.6\%) and stage IA 6 (2.5\%) (Figure 1).

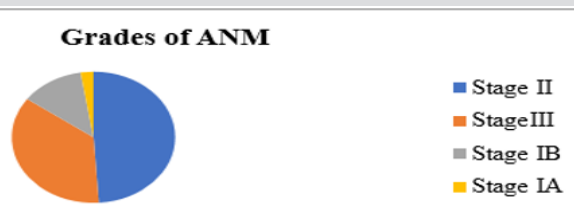

Figure 1: Grades of anterior neck mass among patients at JMC, 2018 G.C.

\section{Thyroid Fuction Tests (TFTs)}

The mean of TSH was $0.95 \pm 49$ and $0.83 \pm 56$ among males and females respectively while the mean of FT3 $(4.58 \pm 38$ vs. $4.27 \pm 86$ vs.) and FT4 (15.47 \pm 92 vs. $14.98 \pm 44)$ among males and females respectively (Table 2 ).

Table 2: Thyroid fuction tests (TFTs) among patients with anterior neck mass at JMC, 2018 G.C.

\begin{tabular}{|c|c|c|}
\hline \multirow{2}{*}{ TFTs } & \multicolumn{2}{|c|}{ Mean \pm SD } \\
\cline { 2 - 3 } & Female & Male \\
\hline TSH, mIU/L & $0.83 \pm 56$ & $0.95 \pm 49$ \\
\hline FT3, pmol/L & $4.58 \pm 38$ & $4.27 \pm 86$ \\
\hline FT4, pmol/L & $15.47 \pm 92$ & $14.98 \pm 44$ \\
\hline
\end{tabular}

\section{Signs and Symptoms Among Patients with Anterior Neck Mass}

The magnitude of signs and symptoms of patients were displayed in Table 3 in detail with highest frequency of heat intolerance $28 \%$, irregular pulse $28 \%$, palpitation $25 \%$, cold intolerance $23 \%$, tachycardia $21 \%$, hypertension $19.3 \%$, weight gain $17.6 \%$, swelling $17.6 \%$, poor memory $17 \%$, weight loss $16.3 \%$ and menstrual irregularity $13.8 \%$ among patients with anterior neck visiting the hospital.

Table 3: Signs and symptoms among patients with anterior neck mass at JMC, 2018 G.C.

\begin{tabular}{|c|c|}
\hline Signs and Symptpms & Frequency (Percentage\%) \\
\hline Heat intolerance & $67(28)$ \\
\hline Cold intolerance & $55(23)$ \\
\hline Weight gain & $42(17.6)$ \\
\hline Weight loss & $39(16.3)$ \\
\hline Irritability/anxiety & $28(11.7)$ \\
\hline Menstrual irregularity & $33(13.8)$ \\
\hline
\end{tabular}

\begin{tabular}{|c|c|}
\hline Dyspnea & $17(7.1)$ \\
\hline Fatigue & $30(12.6)$ \\
\hline Insomnia & $25(10.5)$ \\
\hline Swelling/ edema & $42(17.6)$ \\
\hline Tachycardia & $50(21)$ \\
\hline Irregular pulse & $67(28)$ \\
\hline Palpitation & $60(25)$ \\
\hline Hypertension & $46(19.3)$ \\
\hline Exophthalmos & $29(12)$ \\
\hline Tremor & $37(15.5)$ \\
\hline Abnormal heart sounds & $25(10.5)$ \\
\hline Poor memory & $42(17.6)$ \\
\hline Constipation & $22(9.2)$ \\
\hline Diarrhoa & $15(6.3)$ \\
\hline
\end{tabular}

Types of Thyroid Disorders among Patients with Anterior Neck

Types of thyroid disorders were discriminated based on laboratory results of TFTs and clinical manifestation as other diagnosis criteria (U/S, Echo and FNAC) were not available routinely. Thus, using this diagnostic technique, the discriminated types of thyroid disorders were euthyroidism 83 (34.7\%), subclinical hypothyroidism 46 (19.2\%), sub-clinical hyperthyroidism 42 (17.6\%), hypothyroidism 35 (14.6\%) and hyperthyroidism 33 (13.8\%) (Figure 2).

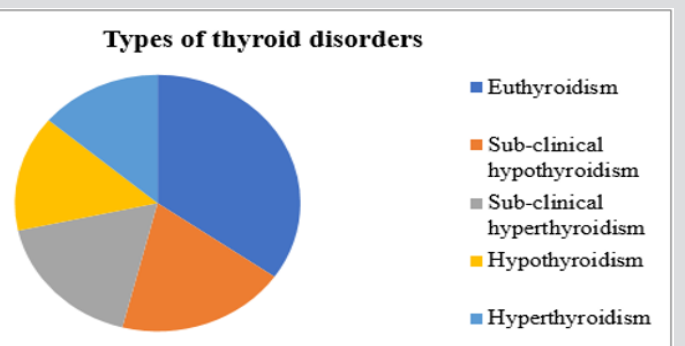

Figure 2: Types of thyroid disorders among patients with anterior neck mass at JMC, 2018 G.C.

\section{Discussion}

In the present study conducted among a total of 239 patients with anterior neck mass, the mean age was $41.83 \pm 17.52 \mathrm{SD}$ years ranged from 18 to 90 years with female 212 (88.7\%) and rural dwellers 155 (64.8\%) dominance. This finding was also supported by different studies who revealed the higher magnitude of the disease among mid age (forties), female and rural dwellers living in the iodine deficient areas [2,8,16-19]. But the mean age of $41.83 \pm 17.52$ SD years was against the finding of Goichot et al. who reported the mean age of $50.6 \pm 85$ SD years [20]. Grading of anterior neck mass/goiter was discriminated that majority of the anterior neck mass patients were belonged to stage II who were about 117 (48.9\%), then stage III 86 (36\%), stage IB 30 (12.6\%) and stage IA $6(2.5 \%)$ as grading was performed according to WHO goiter grading system. This finding was also in harmony with the 
studies of Bimeyna GS et al. who reported that majority of patients were allocated with stage II [21].

The mean of TSH was $0.95 \pm 49$ SD and $0.83 \pm 56$ SD among males and females respectively while the mean of FT3 was $(4.58 \pm 38 \mathrm{SD}$ vs. $4.27 \pm 86 \mathrm{SD})$ and FT4 (15.47 \pm 92 SD vs. $14.98 \pm 44$ SD) among males and females respectively which was also supported by the finding of Knudsen et al. [22]. The present study observed different signs and symptoms among patients with anterior neck visiting outpatient clinic of the hospital. Among these the highest frequency goes to heat intolerance, irregular pulse, palpitation, cold intolerance, tachycardia, hypertension, weight gain, swelling, poor memory, weight loss and menstrual irregularity. This finding was also in harmony with other studies who reported the presence of these signs and symptoms among patients with endocrine disorder $[8,17,20,23,24]$. The type of anterior neck mass/goiter was discriminated as euthyroidism $34.7 \%$, sub-clinical hypothyroidism $19.2 \%$, sub-clinical hyperthyroidism $17.6 \%$, hypothyroidism $14.6 \%$ and hyperthyroidism $13.8 \%$ based on result of TFTs and clinical decision.

Majority of the patients were euthyroidism (34.7\%) who diagnosed with normal laboratory results of TFTs and absence of sign and symptoms being supported by different studies that revealed simple or diffuse or physiological or euthyroidgoitre as the commest among patients with anterior neck mass [2,19,22,25]. Sub-clinical hypothyroidism was observed with higher prevalence (19.2\%) among diagnosed thyroid disorders which was also in harmony with study of Marwaha et al who reported a prevalence of sub-clinical hypothyroidism of $19.3 \%$ [26]. But the present $19.2 \%$ burden of sub-clinical hypothyroidism was against the study of Tekle et al who reported $6.47 \%$ among patients visiting endocrine clinic of Tikur Anbessa hospital [8] and study of Jailkhani et al. who reported sub-clinical hypothyroidism with prevalence of 33\% [27] due to study population difference.

The prevalence of sub-clinical hyperthyroidism was $17.6 \%$ in present study which was also in harmony with the study of Goichot et al. who reported $10.4 \%$ prevalence of subclinical hyperthyroidism [20]. The observed prevalence of hypothyroidism of $14.6 \%$ was in agreement with the prevalence of hypothyroidism of $13.1 \%$ reported by study of Sarfo-Kantanka et al. [18]. The observed magnitude of hyperthyroidism (13.8\%) in the present study was also in line with the study of Monabeka et al. who reported it with prevalence of $20.8 \%$ [28]. Despite the higher prevalence of iodine deficiency thyroid disorder and thyroid malignancy/ lesion reported in the continent, Ethiopia and the setting [16,29-33], the present study was not discriminated them as other means of diagnosis like FNAC, ultrasound and urine iodine analysis not performed which was considered as the limitation of the study.

\section{References}

1. Maenhaut C, Christophe D, Vassart G (2000) Ontogeny, Anatomy, Metabolism and Physiology of the Thyroid. In Feingold KR, Anawalt
B, Boyce A, et al. (eds.). Endotext [Internet]. South Dartmouth (MA): MDText.com, Inc.

2. Vanderpump MP (2011) The epidemiology of thyroid disease. Br Med Bull 99(1): 39-51.

3. Garmendia Madariaga A, Santos Palacios S, Guillén Grima F, Galofré JC (2014) The incidence and prevalence of thyroid dysfunction in Europe: a meta-analysis. J Clin Endocrinol Metab 99(3): 923-931.

4. (2002) Organization WH. The world health report 2002: reducing risks, promoting healthy life. World Health Organization.

5. Garber JR, Cobin RH, Gharib H, Hennessey JV, Klein I, Mechanick JI, et al. (2012) Clinical practice guidelines for hypothyroidism in adults: cosponsored by the American Association of Clinical Endocrinologists and the American Thyroid Association. Endocr Pract 18(6): 988-1028.

6. Surks MI (2005) Subclinical thyroid dysfunction: A joint statement on management from the American Association of Clinical Endocrinologists, the American Thyroid Association, and The Endocrine Society. J Clin Endocrinol Metab 90(1): 586-587.

7. Baskin HJ, Cobin RH, Duick DS, Gharib H, Guttler RB, Kaplan MM, et al. (2002) American association of clinical endocrinologists medical Guidelines for clinical practice for the evaluation and treatment of hyperthyroidism and hypothyroidism: AACE Thyroid Task Force. Endocr Pract 8(6): 457-469.

8. Tekle HA, Bobe TM, Tufa EG, Solomon FB (2018) Age-sex disparities and sub-clinical hypothyroidism among patients in Tikur Anbesa Specialized Hospital, Addis Ababa, Ethiopia. J Health Popul Nutr 37(1): 18.

9. Cooper DS (2001) Subclinical hypothyroidism. N Engl J Med 345(4): 260-265.

10. Surks MI, Ortiz E, Daniels GH, Sawin CT, Col NF, Cobin RH, et al. (2004) Subclinical thyroid disease: scientific review and guidelines for diagnosis and management. Jama 291(2): 228-238.

11. Alam Khan V, Khan MA, Akhtar S (2002) Thyroid disorders, etiology and prevalence. J Med Sci 2(2): 89-94.

12. Toft AD (2001) Subclinical hyperthyroidism. N Engl J Med 345(7): 512 516.

13. Biondi B, Palmieri EA, Klain M, Schlumberger M, Filetti S, Lombardi G (2005) Subclinical hyperthyroidism: clinical features and treatment options. Eur J Endocrinol 152(1): 1-9.

14. Andersson M, Takkouche B, Egli I, Benoist B de (2003) The WHO Global Database on iodine deficiency disorders: the importance of monitoring iodine nutrition. Scand J Nutr 47(4): 162-166.

15. (2010) WHO. Data sources and inclusion criteria for the Database on Iodine Deficiency.

16. Melak T, Abebe M, Tesfaye W, Melku M (2015) Cytological patterns of thyroid lesions at Gondar University Hospital, Northwest Ethiopia: A retrospective study. J Mol Pathophysiol 4(1): 39.

17. Fualal J, Moses W, Jayaraman S, Nalugo M, Ozgediz D, Duh Q-Y, et al. (2012) Characterizing thyroid disease and identifying barriers to care and treatment in Uganda. World J Endoc Surg 4(2): 47-53.

18. Sarfo Kantanka O, Kyei I, Sarfo FS, Ansah EO (2017) Thyroid disorders in central ghana: the influence of 20 years of iodization. J Thyroid Res 1-8.

19. Salami BA, Odusan O, Ebili HO, Akintola PA (2016) Spectrum and prevalence of thyroid diseases seen at a tertiary health facility in Sagamu, South-West Nigeria. Niger Postgrad Med J 23(3): 137.

20. Goichot B, Caron P, Landron F, Bouée S (2016) Clinical presentation of hyperthyroidism in a large representative sample of outpatients in France: relationships with age, aetiology and hormonal parameters. Clin Endocrinol (Oxf) 84(3): 445-451.

21. Bimenya GS, Kaviri D, Mbona N, Byarugaba W (2002) Monitoring the severity of iodine deficiency disorders in Uganda. Afr Health Sci 2(2): 63-68. 
22. Knudsen N, Jørgensen T, Rasmussen S, Christiansen E, Perrild H (1999) The prevalence of thyroid dysfunction in a population with borderline iodine deficiency. Clin Endocrinol (Oxf) 51(3): 361-367.

23. Ogbera AO, Fasanmade O, Adediran O (2007) Pattern of thyroid disorders in the southwestern region of Nigeria. Ethn Dis 17(2): 327.

24. Sidibé EH, Fall L, Sow AM (1997) Clinical characteristics of primary hypothyroidism in Dakar. A study of 37 individuals. Cah Détudes Rech Francoph 7(5): 291-290.

25. Edino ST, Mohammed AZ, Ochicha O (2004) Thyroid gland diseases in Kano. Niger Postgrad Med J 11(2): 103-106.

26. Marwaha RK, Tandon N, Ganie MA, Kanwar R, Sastry A, Garg MK, et al. (2012) Status of thyroid function in Indian adults: Two decades after universal salt iodization. J Assoc Physicians India 60: 32-36.

27. Jailkhani R, Ramachandrayya SA, Patil VS, Sameena (2015) A hospitalbased study of prevalence of thyroid dysfunction in Srinagar, Jammu and Kashmir state of India. Int J Med Sci Public Health 4(2): 151-154.

28. Monabeka HG, Ondzotto G, Peko JF, Kibeke P, Bouenizabila E, NsakalaKibangou N (2005) Thyroid disorders in the Brazzaville Teaching Hospital. Cah Détudes Rech Francoph 15(1): 37-40.

ISSN: 2574-1241

DOI: 10.26717/BJSTR.2019.18.003126

Wondu Reta Demissie. Biomed J Sci \& Tech Res

This work is licensed under Creative Commons Attribution 4.0 License

Submission Link: https://biomedres.us/submit-manuscript.php
29. Ogbera AO, Kuku SF (2011) Epidemiology of thyroid diseases in Africa. Indian J Endocr Metab 15(2): S82-S88.

30. Ersumo T, Fisseha M, Teffera T (2005) Thyroid neoplasms in Tikur Anbessa Hospital, Addis Ababa: a retrospective review with emphasis on cancer. Ethiop Med J 43(4): 273-277.

31. Iddah MA, Macharia BN, Keter A, Ng'wena AG, Fulla AVO (2013) Histological pattern in immunological thyroid disease patients at Moi teaching and referral hospital (mtrh), western Kenya 1(7): 34-44.

32. Dandena A, Teshome MS, Bezabeh M (2018) Prevalence of thyroid cancer among thyroid swelling in Jimma University Medical Center, South West Ethiopia: A five-year retrospective study. Int J Med Med Sci 10(5): 59-64.

33. Negeri Z, Gobena T, Rajesh R, Kassim M (2014) Determining the magnitude of iodine deficiency and its associated risk factors among pregnant women visiting Jimma University specialized hospital for antenatal care. World J Med Med Sci 2: 1-16.

34. Solomon R, Iliyasu Y, Mohammed AZ (2015) Histopathological pattern of thyroid lesions in Kano, Nigeria: A 10-year retrospective review (20022011). Niger J Basic Clin Sci 12(1): 55-60,

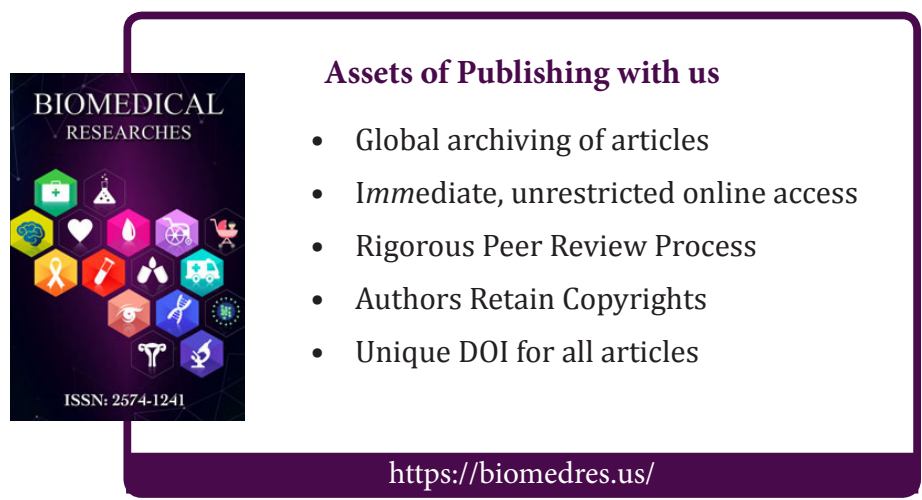

